\title{
Avaliação técnica e econômica da geração distribuída com sistemas fotovoltaicos em edifícios públicos
}

A geração de energia elétrica a partir de fontes renováveis de energia vem ganhando mercado e confiança no mundo e sendo tema de discussões sobre sustentabilidade em fóruns mundiais e locais, e em particular no Brasil, com recentes incentivos regulatórios na geração distribuída. Os edifícios públicos dos municípios gastam montantes consideráveis de recursos financeiros públicos para garantir a eletricidade da administração. Este estudo analisou a viabilidade técnica para o dimensionamento da implantação e operação de sistemas de geração fotovoltaicos em telhados de edifícios e a viabilidade econômica do investimento, através de recursos próprios e de financiamento, para atender a demanda de eletricidade dos serviços e sistemas da administração pública localizados na cidade de Itajubá-MG, como estudo de caso. Os resultados demonstraram a necessidade de haver investimentos iniciais consideráveis e com vantagem econômica mais atrativa de investimento a partir de financiamento. É possível concluir uma grande oportunidade da administração do município em se tornar autossustentável na geração de energia e reinvestir, aproximadamente 1 milhão de reais ao ano em outras áreas do município, com o retorno econômico do sistema após 6 anos no pior cenário analisado.

Palavras-chave: Energia Solar Fotovoltaica; Energia renovável; Sustentabilidade; Administração pública; Geração Distribuída.

\section{Technical and economic evaluation of generation distributed with photovoltaic systems in public buildings}

\begin{abstract}
Electricity generation from renewable energy sources, has been gaining market and confidence in the world and, being the subject of discussions on sustainability in global and local forums, in particular in Brazil, with recent regulatory incentives in the distributed generation. Municipal public authorities spend considerable amounts of public financial resources to guarantee electricity for the administration. This study analyzed the technical feasibility for scaling the deployment and operation of photovoltaic generation systems on the roof of buildings and the economic feasibility of investing through own resources and financing to attend the demand for electricity from public administration services and systems located in the city of Itajubá-MG, as a case study. The results demonstrate a need for a considerable initial investment and with a more attractive economic advantage of investment from financing. It is possible to conclude a great opportunity for the municipality's administration to become self-sustainable in energy generation and to reinvest, approximately R\$ 1 million per year, in other areas of the municipality with the economic return of the system after 6 years in the worst scenario analyzed.
\end{abstract}

Keywords: Photovoltaic Solar Energy; Renewable energy; Sustainability; Public administration; Decentralized Generation.

Topic: Desenvolvimento, Sustentabilidade e Meio Ambiente

Reviewed anonymously in the process of blind peer
Received: 03/03/2021

Approved: $26 / 03 / 2021$
Pedro Marcelo de Moraes Mendonça (it) Universidade Federal de Itajubá, Brasil

http://lattes.cnpq.br/9959703622205975

http://orcid.org/0000-0002-3932-3371

pedro.marcelo.mendonca@gmail.com

Geraldo Lúcio Tiago Filho (id

Universidade Federal de Itajubá, Brasil

http://lattes.cnpq.br/1838249887289555

http://orcid.org/0000-0002-1665-0900

gltiagofilho@gmail.com
Referencing this:

MENDONÇA, P. M. M.; TIAGO FILHO, G. L.. Avaliação técnica e econômica da geração distribuída com sistemas fotovoltaicos em edifícios públicos. Revista Ibero Americana de Ciências Ambientais, v.12, n.3, p.525-539, 2021. DOI: http://doi.org/10.6008/CBPC21796858.2021 .003 .0043 


\section{INTRODUÇÃO}

Foi a partir do início da conscientização ambiental, na década de 1980, que as ideias de desenvolvimento e sustentabilidade começaram a ser associadas. A preservação e conservação do meio ambiente entraram na pauta de discussão global, assim como as medidas que poderiam ser adotadas para abrandar os danos já existentes e impedir os futuros. Uma das soluções encontradas foi a diminuição do uso de energias fósseis, altamente poluentes e amplamente utilizadas, a partir do uso de fontes alternativas renováveis de energia, como a eólica, solar, hídrica e oceânica.

O Brasil possui uma das matrizes energéticas mais limpas do mundo, visto que parte do setor de transportes é por biocombustíveis e o setor elétrico brasileiro é fortemente baseado na hidroeletricidade e, com menor participação, por outras fontes de energias renováveis como a biomassa, a eólica e, mais recentemente, a energia solar. Considerando o cenário futuro, prevê-se que o consumo de energia quase dobre em 2050, passando de 600 TWh/ano para 1.024 TWh/ano, segundo a EPE (2012; 2014), ou seja, todas as medidas para a redução da demanda elétrica e gerações alternativas devem ser consideradas. Porém, diante dos recentes racionamentos de energia, devido às secas em alguns reservatórios de usinas hidrelétricas, fica evidente a necessidade de maiores incentivos e de diversificação do fornecimento de energia, a partir de fontes térmicas e renováveis, tais como a energia eólica e a energia solar. Atualmente, a participação total da matriz brasileira de geração de energia elétrica é proveniente de fontes não renováveis, com $25,6 \%$, e $74,4 \%$ respondem por suas fontes renováveis, das quais a hídrica em sua maior proporção com $63,78 \%, 9,22 \%$ das demais fontes renováveis e 1,4\% da fonte fotovoltaica.

De acordo com Rüther et al. (2011) e Tolmasquim (2016), de toda a energia solar que chega à Terra, aproximadamente metade atinge a superfície, totalizando cerca de 885 milhões de TWh/ano, o que corresponde a 10.000 vezes o consumo mundial de energia no mesmo período. Isso indica que a irradiação solar, além de ser responsável pela manutenção da vida na Terra, também constitui uma fonte energética de recurso inesgotável, com um enorme potencial de utilização por meio de sistemas de captação e conversão em outras formas de energia, principalmente a térmica e a elétrica.

Conforme o Banco de Informações de Geração da ANEEL (2020), embora o Brasil tenha avançado nos últimos anos, disponibilizando consideráveis incentivos e com grande número de sistemas fotovoltaicos implantados no período de 2012 a 2020, com recorde de projetos cadastrados de oferta no leilão A-6 em 2019, continua com um mercado ainda muito pequeno e ainda há muito a ser feito para consolidar a fonte solar fotovoltaica na matriz energética nacional. As condições climáticas e de irradiação no Brasil, detentor de um dos melhores recursos solares do planeta, com irradiação solar média anual de $1.986 \mathrm{kWh} / \mathrm{m}^{2}$ ao ano, também colaboram e aumentam o potencial em relação ao uso de sistemas solares fotovoltaicos. Enquanto isso, a liderança de outros países em potencial de sistemas fotovoltaicos instalados é bem superior, como no caso da Alemanha, com irradiação solar média anual de $1.251 \mathrm{kWh} / \mathrm{m}^{2}$ ao ano e com $7,2 \%$ de participação da energia solar fotovoltaica em sua matriz energética, conforme ilustra a Figura 1.

Devido ao cenário econômico atual e incentivos regulatórios no Brasil, tanto as instituições privadas 
como a população em geral, buscam a redução de gasto energético e também a necessidade de aumentar eficiência tanto nas suas atividades produtivas como no uso dos recursos naturais e energéticos. E de forma ainda bem discreta, as edificações públicas - escolas, prefeituras e outros prédios públicos - representam apenas 1,3\% da geração distribuída, com grande potencial em se tornarem unidades que possam gerar a sua própria energia (ANEEL, 2020). Em meados do mês de maio de 2020, a usina fotovoltaica instalada no edifíciosede da Prefeitura de Belo Horizonte entrou em funcionamento, com uma potência instalada de $65 \mathrm{kWp}$, que representa apenas $20 \%$ do consumo do edifício-sede da Prefeitura, ainda muito a se ampliar considerando-se as demais edificações da capital do estado de Minas Gerais.

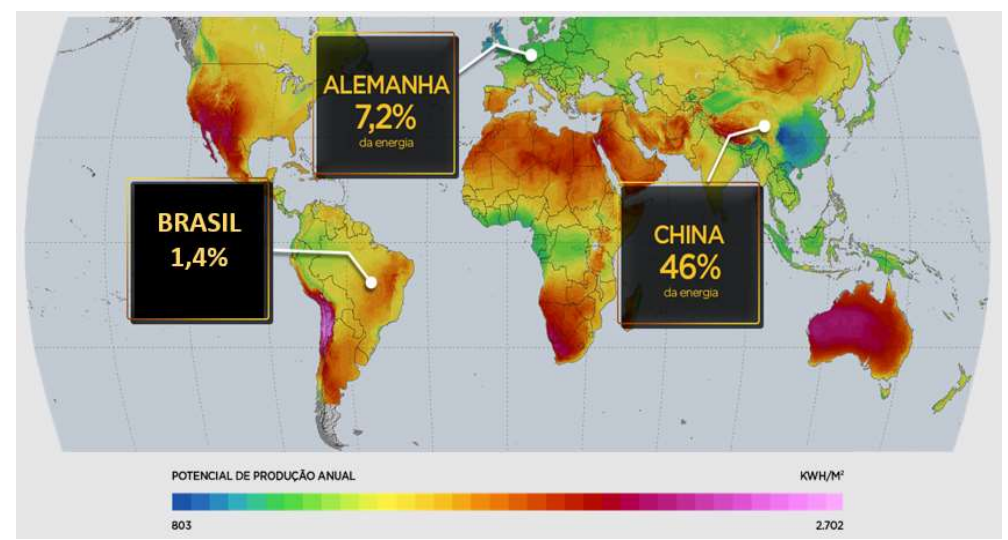

Figura 1: Comparativo da participação de sistemas fotovoltaicos nas matrizes energéticas do Brasil, Alemanha e China.

Este estudo tem como objetivo analisar a viabilidade técnica e econômica para geração distribuída com sistemas fotovoltaicos em edifícios públicos a fim de incentivar a implantação destes sistemas, trazendo como estudo de caso o município de Itajubá-MG.

\section{METODOLOGIA}

Neste trabalho, foi desenvolvido um estudo de caso do município de Itajubá - MG. Trata-se de um município de porte médio, com 97.000 habitantes, população estimada no ano de 2020 pelo IBGE, situado ao sul do estado de Minas Gerais, Brasil, a 836 metros de altitude, localizado de acordo com as seguintes coordenadas geográficas: Latitude de $22^{\circ} 25^{\prime} 37^{\prime \prime}$ Sul, Longitude de $45^{\circ} 27^{\prime} 11^{\prime \prime}$ Oeste, conforme Figura 2.

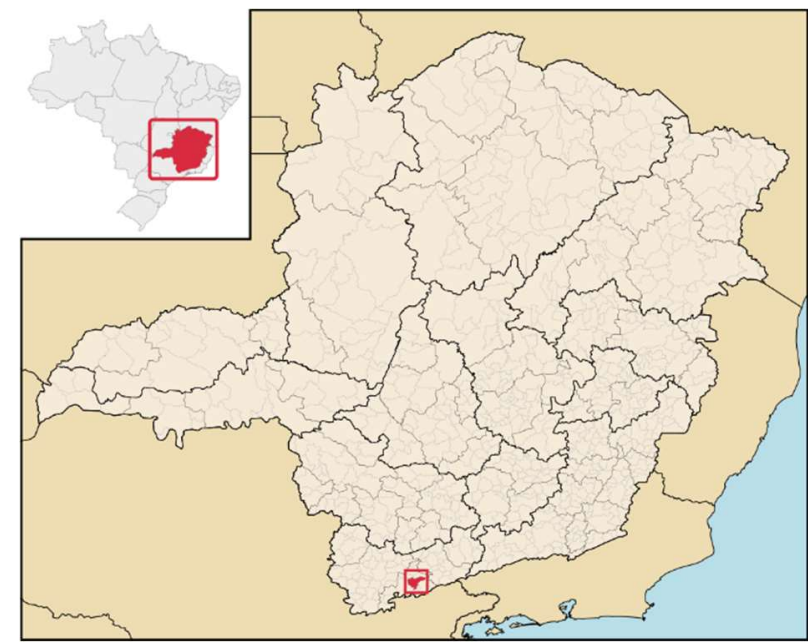

Figura 2: Mapa da localização do município de Itajubá-

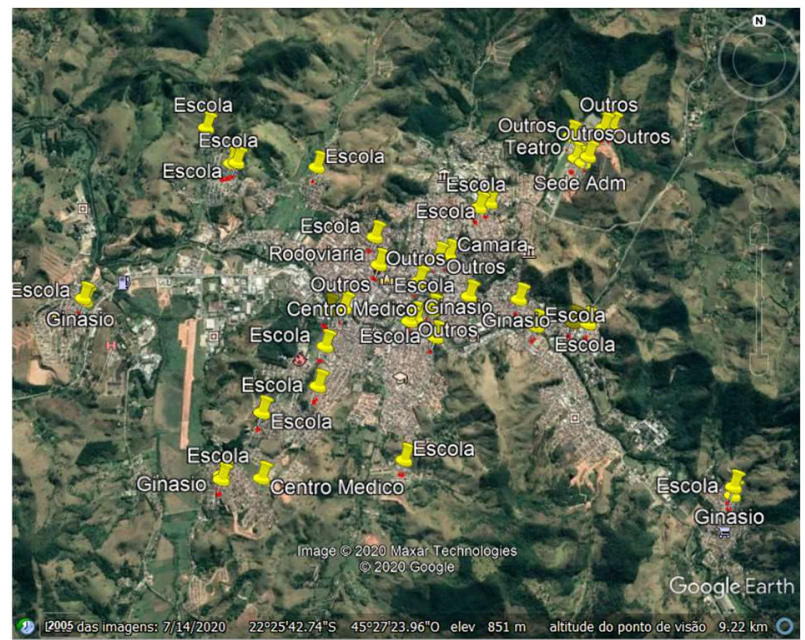

Figura 3: Localização dos edifícios da administração 
MG.

pública de Itajubá-MG.

Para identificar os edifícios públicos próprios da prefeitura, foi necessário identificar os edifícios que são de propriedade da administração pública e o espaço disponível nos telhados para calcular o potencial total de geração de energia fotovoltaica nesses edifícios. Os endereços dos edifícios foram obtidos através do relatório atualizado dos imóveis, fornecido pela secretaria de planejamento do município de Itajubá-MG e foi identificado um total de 55 telhados para instalação do sistema fotovoltaico. Utilizando-se do sistema web do Google Earth ${ }^{\circledR}$, foram localizados geograficamente: 34 Escolas, 5 Ginásios, Mercado Municipal, Câmara Municipal, Teatro, Sede Administrativa e 11 outros edifícios públicos, conforme identificados na Figura 3.

Os dados das áreas de cada telhado foram obtidos através de medições aproximadas, utilizando-se do sistema web do Google Earth, inserindo as delimitações de cada telhado. Foi identificado uma disponibilidade de área de telhado de $43.566 \mathrm{~m}^{2}$ nos 55 edifícios e, para evitar possíveis áreas de sombreamentos e garantir a inclinação para o norte, foi considerada uma ocupação máxima de cada telhado de $40 \%$ da área total disponível para implantação do sistema fotovoltaico, ou $17.426 \mathrm{~m}^{2}$ de área para implantação do sistema fotovoltaico em 55 edifícios, conforme exemplificado pela Figura 4.

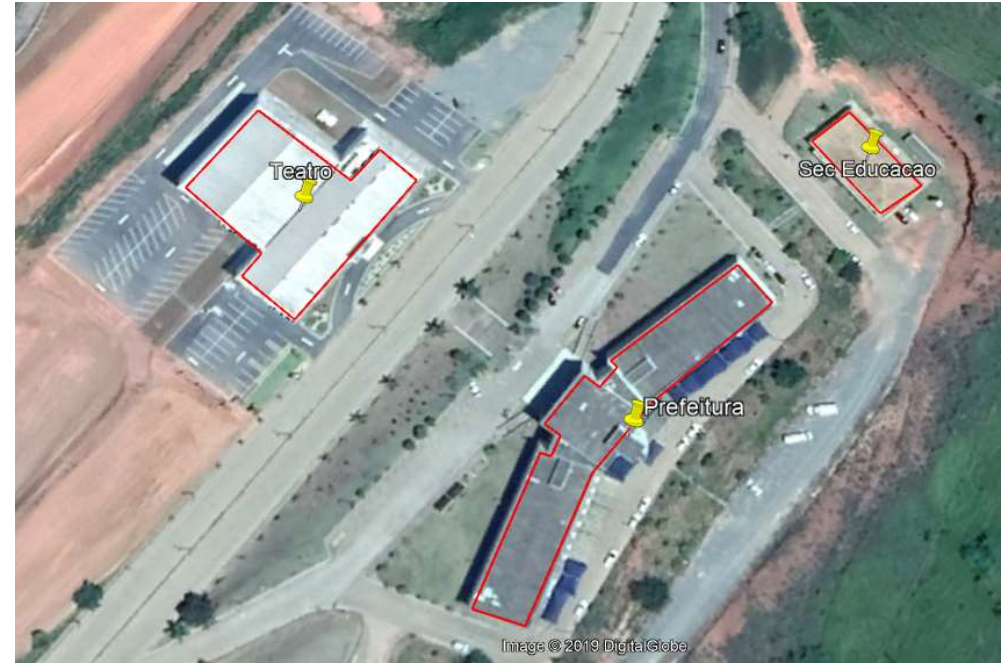

Figura 4: Determinação da área dos telhados dos 55 edifícios.

\section{Cálculo do potencial energético das edificações selecionadas}

Segundo Carvalho et al. (2019), com a avaliação da área disponível ou útil de cada telhado dos prédios públicos, é possível mensurar as quantidades de placas fotovoltaicas que podem ser utilizadas em cada localidade através da Equação 3.1 e assim calcular o potencial de geração energética de uma determinada área disponível para a instalação do sistema. Deve-se arredondar a quantidade de módulos para um número inteiro menor que o obtido.

$$
\mathrm{Q}_{p}=\frac{\mathrm{A}_{u}}{A_{p}}
$$

Onde:

Qp: Quantidade de placas; Au: Área útil $\left[\mathrm{m}^{2}\right]$; e $A_{p}$ : Área da placa $\left[\mathrm{m}^{2}\right]$. 
De posse da quantidade de placas, é possível calcular a Potência do Sistema Pcc - [kWp], conforme Equação 3.2.

$$
P_{c c}=Q_{p} \cdot P_{p}
$$

Onde:

$P_{c c}$ : Potência do Sistema [kWp];

$Q_{p}$ : Quantidade de placas; e

$P_{p}$ : Potência nominal da placa $[\mathrm{Wp}]$.

A Geração Média ao dia [kWh/dia] por módulo fotovoltaico é dada pela Equação 3.3.

$$
G_{m d}=A_{p} \cdot G_{m} \cdot \eta \cdot R
$$

Onde:

$\mathrm{G}_{\mathrm{md}}$ : Geração Média ao dia por módulo [kWh/dia]; $A_{p}$ : Área da placa $\left[\mathrm{m}^{2}\right]$ - especificação do fabricante; $\mathrm{G}_{\mathrm{m}}$ - irradiação solar [kWh/dia. $\left.\mathrm{m}^{2}\right]$;

$\mathrm{R}$ - Performance do Sistema - devido às perdas causadas pelo aumento de temperatura nas placas, inclinação das placas, rendimento do inversor, sombreamentos. Como referência, utiliza-se $80 \%$; e

$\eta$ - Rendimento do módulo - especificação do fabricante.

Para os cálculos de um sistema fotovoltaico, é necessário, primeiramente, a escolha do módulo, e com as especificações do módulo é possível desenvolver os cálculos. O módulo deve ser escolhido em função da sua qualidade, certificado pelo Procel/Inmetro, ISO 9001 e disponibilidade no mercado. Para este estudo, levou-se em conta a especificação da placa fotovoltaica do fabricante Trina Solar, modelo Tallmax TSM-405 - DE15M(II), de área de 2,03 m² (2024mmx1004mm), de silício policristalino com classificação de eficiência energética 'A' pelo INMETRO e potência nominal de $405 \mathrm{Wp}$, cujas características estão detalhadas na Tabela 1.

\begin{tabular}{|c|c|}
\hline Fabricante & Trina Solar \\
\hline Modelo & Tallmax TSM-405 \\
\hline Tipo & Policristalino \\
\hline Potência & $405 \mathrm{~W}$ \\
\hline n Módulo & $19,9 \%$ \\
\hline Imáx & $10 \mathrm{~A}$ \\
\hline Vmáx & $40,5 \mathrm{~V}$ \\
\hline Isc/Icc & $10,52 \mathrm{~A}$ \\
\hline Voc/Vca & $49,2 \mathrm{~V}$ \\
\hline Peso & $22,8 \mathrm{~kg}$ \\
\hline Área $\left(m^{2}\right)$ & 2,03 \\
\hline Dimensões (mm) & $2024 \times 1004 \times 35$ \\
\hline Máx. Corr. Fusível (série) & $20 \mathrm{~A}$ \\
\hline Coef. Temperatura $/{ }^{\circ} \mathrm{C}$ & $-0,37 \%$ \\
\hline Depreciação ao ano & $0,80 \%$ \\
\hline
\end{tabular}

Tabela 1: Especificações da placa fotovoltaica

A irradiação solar $\left(G_{m}\right)\left[\mathrm{kWh} /\right.$ dia. $\left.\mathrm{m}^{2}\right]$ foi obtida através de banco de dados do CRESESB (Centro de Referência para Energia Solar e Eólica Sérgio de Salvo Brito), que dispõe de informações de irradiação solar no Brasil por localidade, e conforme a média anual da irradiação para a latitude da instalação. A Figura 5 é o resultado da irradiação diária média por mês para o plano horizontal e para inclinação dos módulos a $22^{\circ}$ para o norte, ângulo adotado igual à latitude do município de Itajubá - MG para obter a máxima eficiência do sistema. 


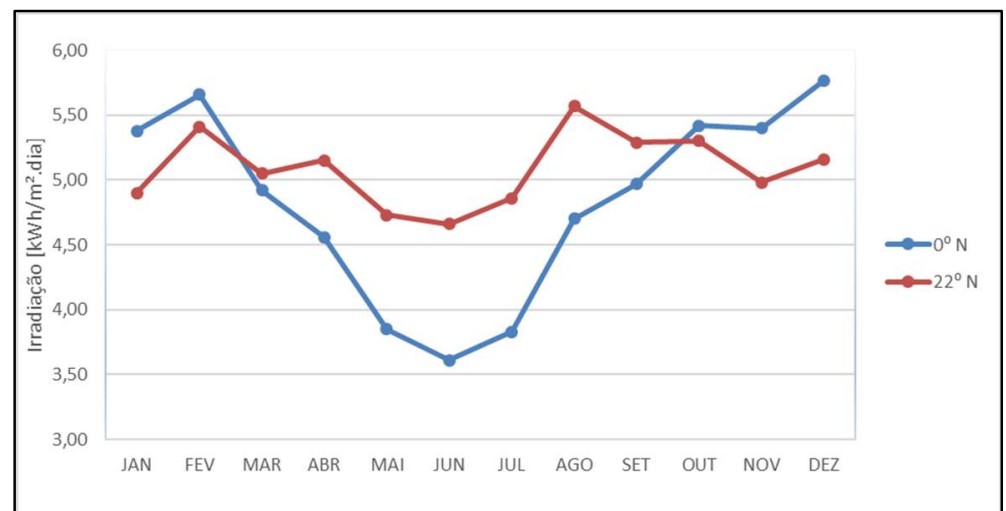

Figura 5: Irradiação solar incidente para o plano horizontal e para o plano com inclinação igual à latitude do município de Itajubá-MG.

A fim de minimizar elevados investimentos iniciais para atender toda a administração pública, e principalmente realizar o projeto para que seja licitado através da modalidade de registro de preço onde não há necessidade nem obrigatoriedade de aquisição imediata de todos os equipamentos e também a possível adesão à ata de registro por outros entes públicos, caso haja interesse, foi considerada a implantação de um sistema modular, ou kits, que podem ser conectados entre si na mesma rede elétrica, uma vez que os inversores permitem essa interconexão. Para composição do sistema modular, foi então considerado um inversor de 4 kW, da Fronius, modelo 4.0-1 que opera com uma tensão de entrada de 80 Vcc até 800 Vcc, conforme especificação na Tabela 2. Para que o inversor não trabalhe no limite máximo de tensão da especificação para entrada $V c c$, considerou-se um conjunto de 12 placas ligadas em série, que fornecerá 493 Vcc e $10 \mathrm{~A}$ - cada placa fornece 40,5 Vmax e $10 \mathrm{~A}$ - totalizando 210 inversores.

Tabela 2: Especificações do inversor.

\begin{tabular}{ll}
\hline Marca/Modelo & FRONIUS 4.0-1 \\
\hline Tensão máxima de entrada & $800 \mathrm{Vcc}$ \\
\hline Tensão mínima de entrada & $80 \mathrm{Vcc}$ \\
\hline Corrente máxima de entrada & $12 \mathrm{~A}$ \\
\hline Tensão de saída & $230 \mathrm{Vca}$ \\
\hline Frequência de saída & $60 \mathrm{~Hz}$ \\
\hline Corrente máxima de saída & $17,4 \mathrm{~A}$ \\
\hline Potência nominal & $4000 \mathrm{~W}$ \\
\hline Eficiência máxima & $98,1 \%$ \\
\hline
\end{tabular}

\section{Levantamento da demanda energética e de gastos energéticos das edificações selecionadas}

Através de dados de consumo de energia obtidos na Prefeitura Municipal de Itajubá - MG, foram identificadas 189 unidades de consumo de energia, incluindo os 55 edifícios identificados para a instalação, um total de 24 escolas, 12 creches, 20 postos de saúde, 58 edificações (teatro, rodoviária, Mercado Municipal, Câmara legislativa, ginásios e outros) e 75 locais de iluminações de praças e avenidas, as quais não fazem parte da iluminação pública. Devido às regulamentações e leis que regem o consumo e pagamento de energia de forma diferenciada, se comparada ao consumo de energia convencional, não foi possível incluir neste levantamento e no projeto, o consumo com a iluminação pública, que é de $5 \mathrm{GWh} /$ ano, bem como o consumo da sede da prefeitura, onde o fornecimento é sob demanda de alta tensão contratual e o qual não é possível a rescisão sem incidência de multa. 
O consumo médio de todas as 189 unidades consumidoras, conforme contas da concessionária CEMIG colhidas na Prefeitura de Itajubá, é de 1,5 GWh/ano e de 1,4 GWh/ano, deduzindo o consumo mínimo bifásico de $50 \mathrm{kWh} /$ mês por ponto de consumo, das quais 55 unidades serão geradoras e também consumidoras, e os créditos da geração fotovoltaica excedente gerada por essas unidades serão compartilhadas com as demais unidades que estão no mesmo cadastro de pessoa jurídica da Prefeitura. Através de valores de tarifas com impostos praticados pela concessionária CEMIG por kWh nas faturas, serão poupados, ao ano, pela geração do sistema fotovoltaico, o valor corresponde a mais de 1 milhão de reais, conforme Tabela 3.

Tabela 3: Consumo médio de energia [kWh] e valor consumido.

\begin{tabular}{|c|c|c|c|c|c|c|c|}
\hline TIPO & $\begin{array}{l}\text { Média } \\
\text { kWh/mês }\end{array}$ & $\begin{array}{l}\text { kWh/ano } \\
\text { (1) }\end{array}$ & $\begin{array}{l}\text { Número } \\
\text { de Pontos }\end{array}$ & $\begin{array}{l}\text { Consumo } \\
\text { mínimo } \\
\text { kWh/ano (2) }\end{array}$ & $\begin{array}{l}\text { Consumo (1) } \\
\text { - mínimo (2) }\end{array}$ & $\begin{array}{l}\text { Tarifas com } \\
\text { impostos }\end{array}$ & $\begin{array}{l}\text { Valor a ser } \\
\text { poupado }\end{array}$ \\
\hline ESCOLAS & 17.098 & 205.173 & 24 & 14.400 & 190.773 & 0,75 & $\mathrm{R} \$ 143.806,33$ \\
\hline CRECHES & 9.220 & 110.634 & 12 & 7.200 & 103.434 & 0,75 & $\mathrm{R} \$ 77.969,44$ \\
\hline EDIFÍCIOS - OUTROS & 46.941 & 563.296 & 58 & 34.800 & 528.496 & 0,75 & $\mathrm{R} \$ 398.384,84$ \\
\hline POSTOS DE SAÚDE & 9.830 & 117.961 & 20 & 12.000 & 105.961 & 0,75 & $\mathrm{R} \$ 79.874,31$ \\
\hline IP - AVENIDAS & 7.827 & 93.921 & 7 & 4.200 & 89.721 & 0,75 & $\mathrm{R} \$ 67.632,46$ \\
\hline IP - SERVIÇOS & 3.649 & 43.785 & 8 & 4.800 & 38.985 & 0,75 & $\mathrm{R} \$ 29.387,23$ \\
\hline IP - PRAÇA & 31.225 & 374.695 & 60 & 36.000 & 338.695 & 0,75 & $\mathrm{R} \$ 255.311,21$ \\
\hline TOTAL & 125.789 & 1.509 .465 & 189 & 113.400 & 1.396 .065 & 0,75 & $\mathrm{R} \$ 1.052 .365,82$ \\
\hline
\end{tabular}

\section{Análise da viabilidade econômica}

O maior entrave para a disseminação do mercado de sistemas fotovoltaicos no Brasil é devido ao alto investimento inicial para a instalação do sistema e pouca oferta de linhas de créditos atrativos ou subsídios de impostos dos materiais (HOLDERMANN et al., 2014). Para análise da composição dos cálculos, foram realizados dois cenários para o investimento inicial: com recursos próprios e através de financiamento disponível.

A análise da viabilidade econômica para a instalação do sistema fotovoltaico foi realizada através dos métodos do Payback (PB), do Valor Presente Líquido (VPL), da Taxa Interna de Retorno (TIR) e do Custo Nivelado de Energia (LCOE - do inglês Levelized Cost of Energy) e para isso foi necessário levantamento dos valores dos: investimentos iniciais para instalação do sistema; custos com manutenção, que segundo EPE (2018), é de 0,5\% do investimento ao ano; taxa mínima de atratividade (TMA). Para esse estudo, foi considerado o valor da taxa de reajuste tarifário anual da concessionária CEMIG, que entre os anos de 2011 a 2020, foi em média de 6,46\% ao ano (ANEEL, 2020); e Outro fator importante para o cálculo do retorno do investimento é o cálculo com linha de crédito disponível.

\section{Método do payback}

Segundo Bhandari et al. (2015), o payback, ou retorno de investimento, é uma técnica muito utilizada em sistemas elétricos e de eficiência energética para analisar a sua viabilidade. O cálculo do período de retorno do capital investido, payback, mede o prazo necessário para se recuperar o investimento inicial, levando em conta a economia anual proporcionada pelo sistema de geração, o tempo de vida útil deste 
empreendimento em anos, a taxa de desconto e o fator de recuperação do capital inicial.

Há duas formas de cálculo do payback: - Payback Simples: considera apenas o retorno obtido através da economia que a instalação do sistema de geração irá proporcionar na fatura de energia do consumidor. Para esse cálculo, é verificado apenas o tempo de recuperação do investimento inicial e o lucro obtido durante o período de vida útil da instalação. Não é considerada a correção monetária ao longo do tempo; Payback Descontado: utiliza o mesmo conceito do cálculo do Payback Simples, porém, nesse cenário são considerados os valores da taxa de desconto, a correção monetária ao longo do tempo e o fator de recuperação do capital inicial.

\section{Método do valor presente líquido}

Conforme Bhandari et al. (2015), para realizar o cálculo do VPL, é considerado o valor do dinheiro no tempo, pois todos os valores de entradas e saídas de caixa são tratados no instante presente. Pode-se dizer também que é a projeção dos valores no futuro, realizando os somatórios do investimento inicial ao retorno do sistema, o quanto estaria valendo no presente momento.

O termo líquido é um indicador referente à diferença entre o valor presente dos capitais positivos e os capitais negativos do fluxo de caixa. Logo, o investimento torna-se atrativo a partir de um VPL positivo e determina o valor no momento inicial de uma operação, considerando um fluxo de caixa composto de receita e dispêndios, descontados com a Taxa Mínima de Atratividade (TMA), conforme Equação 3.4 (TALAVERA et al., 2010).

$$
V P L=-\mathrm{I}_{0}+\sum_{\mathrm{t}=1}^{\mathrm{n}} \frac{\mathrm{FC}_{\mathrm{t}}}{(1+\mathrm{i})^{\mathrm{t}}}
$$

Onde:

$\mathrm{I}_{0}$ é o Investimento Inicial; FC é o fluxo de caixa no período; t é o enésimo período no tempo em que o dinheiro será investido no projeto (começa no período 1, quando há efetivamente o primeiro fluxo de dinheiro); n é o número de períodos; e i é o custo do capital.

\section{Método da Taxa Interna de Retorno (TIR)}

A TIR é a rentabilidade, ou percentual de recurso ganho sobre a aplicação de um investimento. É a taxa necessária para tornar nulo o VPL de um investimento no período considerado, demostrada pela Equação 3.5 (TALAVERA et al., 2010).

$$
V P L=0 \Rightarrow I_{0}=\sum_{t=1}^{n} \frac{F C_{t}}{(1+\mathrm{TIR})^{t}}
$$


n é o número de períodos; e i é o custo do capital.

Entre duas alternativas econômicas com TIR diferentes, a que tiver a maior taxa significa que o investimento vai proporcionar maior retorno. $\mathrm{O}$ investimento será economicamente atraente apenas se a TIR for maior que a Taxa Mínima de Atratividade -TMA.

\section{Custo nivelado de energia (LCOE)}

O LCOE é utilizado para comparar o custo relativo da energia produzida por diferentes fontes de geração de energia e tem como objetivo representar o custo por kWh gerado pelo investimento [R\$/kWh], tornando-se atrativo quanto menor for em relação à tarifa praticada pela concessionária. A metodologia básica de cálculo do LCOE é descrita pela Equação 3.6 (ONDRACZEK et al., 2015).

$$
L C O E=\frac{\mathrm{I}_{0}+\text { Manutenção }}{\text { Geração Total }}
$$

Onde:

$\mathrm{I}_{0}$ é o Investimento Inicial;

Manutenção: todos os custos necessários para manter o sistema produzindo durante todo seu ciclo de vida útil; e Geração Total: geração produzida pelo investimento durante todo o ciclo de vida útil [kWh].

\section{RESULTADOS E DISCUSSÃO}

\section{Potencial energético}

A Tabela 4 apresenta o que cada módulo fotovoltaico escolhido é capaz de produzir: uma média de 1,65 kWh por dia ou de 50,13 kWh por mês.

Tabela 4: Cálculo da geração energética por módulo fotovoltaico

\begin{tabular}{|c|c|c|c|c|}
\hline Mês & $\begin{array}{lcc}\mathrm{C}_{\mathrm{md}} & - & \text { Geração } \\
\text { diária por modulo }(\mathrm{kWh})\end{array}$ & média & $\begin{array}{l}\text { Geração } \\
\text { mensal por módulo (kWh) }\end{array}$ & média \\
\hline Janeiro & 1,59 & & 49,14 & \\
\hline Fevereiro & 1,75 & & 49,01 & \\
\hline Março & 1,63 & & 50,65 & \\
\hline Abril & 1,67 & & 49,98 & \\
\hline Maio & 1,53 & & 47,44 & \\
\hline Junho & 1,51 & & 45,23 & \\
\hline Julho & 1,57 & & 48,74 & \\
\hline Agosto & 1,80 & & 55,86 & \\
\hline Setembro & 1,71 & & 51,34 & \\
\hline Outubro & 1,72 & & 53,35 & \\
\hline Novembro & 1,62 & & 48,62 & \\
\hline Dezembro & 1,68 & & 52,15 & \\
\hline Média & 1,65 & & 50,13 & \\
\hline Total Ano & 19,78 & & 601,50 & \\
\hline
\end{tabular}

Com o sistema fotovoltaico implantado nos 55 edifícios, na área útil total de $17.426 \mathrm{~m}^{2}(40 \%$ de aproveitamento de área de cada telhado), é possível instalar 8.582 placas fotovoltaicas de $405 \mathrm{Wp}$, com área de 2,03m, totalizando um potencial energético de 3,47 MW, ou 5,1 GWh ao ano, atendendo a necessidade de consumo de 1,4 GWh/ano para os 189 pontos e enquadrando o sistema fotovoltaico em uma minigeração distribuída, conforme resultado da Tabela 5. 
Tabela 5: Cálculo da potência do sistema.

\begin{tabular}{|c|c|c|c|c|c|}
\hline & 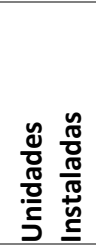 & $\begin{array}{l}\text { E్ } \\
\underset{\mathbb{d}}{\mathbb{d}} \\
\frac{\pi}{<}\end{array}$ & 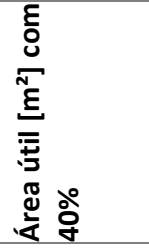 & 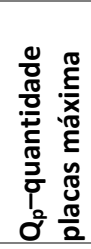 & 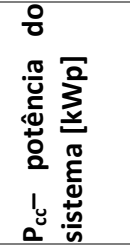 \\
\hline Escolas & 34 & $25.912,00$ & $10.364,80$ & 5.105 & 2067,53 \\
\hline Mercado Municipal & 1 & $2.071,00$ & 828,40 & 408 & 165,24 \\
\hline Câmara Municipal & 1 & 320,00 & 128,00 & 63 & 25,52 \\
\hline Prefeitura - Sede Administrativa & 1 & $1.496,00$ & 598,40 & 294 & 119,07 \\
\hline Estação Rodoviária & 1 & $1.300,00$ & 520,00 & 256 & 103,68 \\
\hline Teatro & 1 & $1.716,00$ & 686,40 & 338 & 136,89 \\
\hline Ginásios & 5 & $5.538,00$ & $2.215,20$ & 1.091 & 441,86 \\
\hline Outros edifícios públicos & 11 & $5.213,00$ & $2.085,20$ & 1.027 & 415,94 \\
\hline TOTAL & 55 & $43.566,00$ & $17.426,40$ & 8.582 & $3.475,71$ \\
\hline
\end{tabular}

\section{Cálculo para atender a demanda do consumo}

Para atender a demanda do consumo de 1,4 GWh/ano dos 189 pontos, a ocupação útil passou de 40\% para $11 \%$ do telhado dos 55 edifícios. Para minimizar os impactos da degradação anual de 0,8\% do rendimento dos módulos fotovoltaicos, houve um incremento de $10 \%$ na geração, garantindo a média de geração igual ao consumo para o período de 25 anos. Assim, serão necessários 2.556 módulos fotovoltaicos, com potência total do sistema de 1,035 MW, gerando uma média de 1,54GWh/ano, conforme Figura 6.

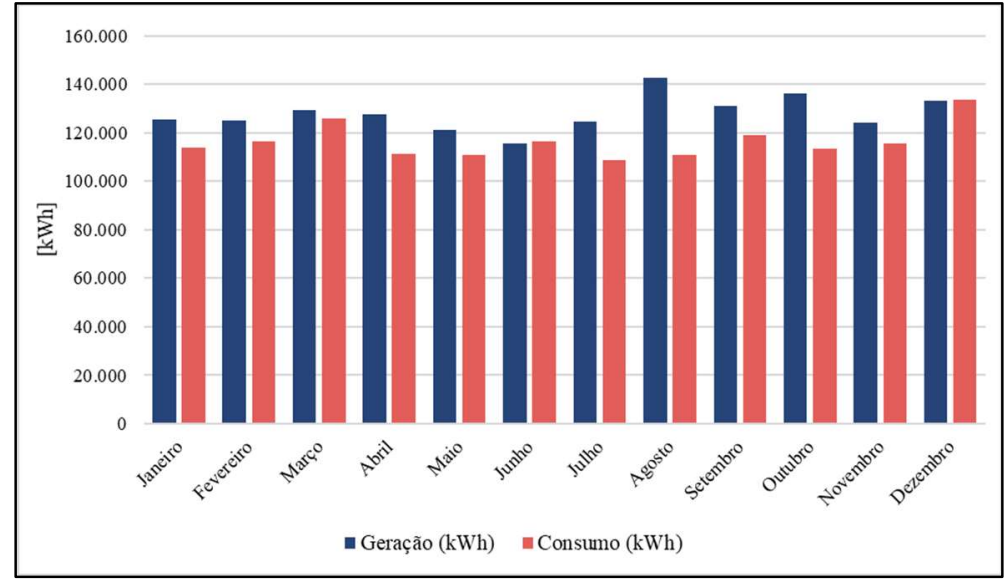

Figura 6: Geração x consumo.

Na Tabela 6, está apresentada a estimativa de mercado do investimento de quase 3,7 milhões de reais para a implantação do sistema fotovoltaico nos 55 pontos candidatos, o que corresponde a uma usina de $1 \mathrm{MW}$, ou em outras palavras quase 1,54 GWh/ano gerados a partir de um sistema fotovoltaico composto por 210 sistemas modulares.

Tabela 6: Valor estimado do sistema.

\begin{tabular}{llll}
\hline Quantidade & Material & Unitário & Parcial \\
\hline $\mathbf{2 . 5 5 6}$ & Módulo Policristalino 405 Wp & $\mathrm{R} \$ 825,00$ & $\mathrm{R} \$ 2.108 .700,00$ \\
\hline $\mathbf{2 1 0}$ & Inversor Fronius PRIMO 4.0-1 & $\mathrm{R} \$ 5.200,00$ & $\mathrm{R} \$ 1.092 .000,00$ \\
\hline $\mathbf{7 4 5 3}$ & Metro de Cabo CC & $\mathrm{R} \$ 6,10$ & $\mathrm{R} \$ 45.465,63$ \\
\hline $\mathbf{2 1 0}$ & Protetor surto CC & $\mathrm{R} \$ 300,00$ & $\mathrm{R} \$ 63.000,00$ \\
\hline $\mathbf{2 1 0}$ & Protetor surto CA & $\mathrm{R} \$ 158,64$ & $\mathrm{R} \$ 33.314,35$ \\
\hline $\mathbf{8 4 0}$ & Conector 6 mm (2 $^{2}$ & $\mathrm{R} \$ 3,00$ & $\mathrm{R} \$ 2.520,00$ \\
\hline $\mathbf{2 1 0}$ & Disjuntor CA & $\mathrm{R} \$ 80,00$ & $\mathrm{R} \$ 16.800,00$ \\
\hline $\mathbf{2 1 0}$ & Disjuntor CC & $\mathrm{R} \$ 230,00$ & $\mathrm{R} \$ 48.300,00$ \\
\hline
\end{tabular}




\begin{tabular}{llll}
\hline $\mathbf{2 1 0}$ & Fixação estrutura metálica & $\mathrm{R} \$ 400,00$ & $\mathrm{R} \$ 84.000,00$ \\
\hline $\mathbf{2 1 0 0 0}$ & Metro de cabo de cobre $2,5 \mathbf{m m}^{2}$ & $\mathrm{R} \$ 0,90$ & $\mathrm{R} \$ 18.900,00$ \\
\hline $\mathbf{2 1 0}$ & Outros equipamentos para instalação & $\mathrm{R} \$ 200,00$ & $\mathrm{R} \$ 42.000,00$ \\
\hline $\mathbf{2 1 0}$ & Instalação & $\mathrm{R} \$ 500,00$ & $\mathrm{R} \$ 105.000,00$ \\
\hline $\mathbf{2 1 0}$ & Projeto, regularização e ART & $\mathrm{R}$ 250,00 & $\mathrm{R} \$ 52.500,00$ \\
\hline- & Total & - & $\mathbf{R} \mathbf{3 . 7 1 2 . 4 9 9 , 9 8}$ \\
\hline- & Valor por kit & - & $\mathbf{R} \mathbf{1 7 . 6 7 8 , 5 7}$ \\
\hline- & Valor por $\mathbf{k W}$ & - & $\mathbf{R} \mathbf{3 . 5 8 6 , 3 3}$ \\
\hline
\end{tabular}

O valor estimado do mercado local por $\mathrm{kW}$ foi de $\mathrm{R} \$ 3.586,33$ para um sistema de um pouco mais de $1 \mathrm{MW}$. Segundo estudo de mercado com 2.104 empresas integradoras de sistema fotovoltaico, realizado pela Greener, empresa que estuda o mercado para apoio à empreendedores e investidores de energia no Brasil, o valor comercializado para o cliente final para potência instalada é, em média, de R\$ 4.100,00 por kW para instalações de até $8 \mathrm{~kW}$ a R\$ 3.400,00 por kW para instalações de até $1 \mathrm{MW}$.

\section{Cálculo dos indicadores econômicos}

Os cálculos foram realizados em 3 cenários distintos de investimento: com recurso próprio integral no início do projeto; com financiamento através de linha de crédito; e, por último, com recurso próprio investido gradualmente e pelo período de 7 anos iniciais, com aquisição de 30 kits anuais.

O valor da receita oriunda da economia média anual com a implantação do sistema fotovoltaico é de R\$ 1.052.365,82 para os 12 primeiros anos de produção, onde o sistema irá suprir a energia consumida com a implantação de todo o sistema fotovoltaico. Para aquisição gradual do sistema em 7 anos, a geração de energia irá suprir parte da demanda nos 7 primeiros anos, e entre o 70 e o 15으 ano suprirá a demanda total. A partir do 13ㅇan ano, com a implantação de todo o sistema e a partir do 16ㅇa ano com a implantação gradual em 7 anos, a produção passa a ser menor que o consumo, devido à degradação da eficiência do painel fotovoltaico de $0,8 \%$ ao ano. A receita oriunda da geração cairá na mesma proporção da degradação dos painéis fotovoltaicos.

O investimento inicial de todo o projeto é de $R \$ 3.712 .499,93$, e esse valor também é utilizado nos próximos cálculos para realizar a análise econômica de acordo com o Payback (PB), o Valor Presente Líquido (VPL), a Taxa Interna de Retorno (TIR) e LCOE, e para esses cálculos é importante considerar a Taxa Mínima de Atratividade (TMA). A Tabela $7 \mathrm{faz}$ um resumo de todos os dados necessários para os cálculos da viabilidade econômica.

Tabela 7: Resumo dos dados para os cálculos da viabilidade econômica.

\begin{tabular}{ll}
\hline Investimento Inicial Total & $\mathrm{R} \$ 3.712 .499,93$ \\
\hline Receita Inicial para lo (anual) & $\mathrm{R} \$ 1.052 .365,82$ \\
\hline Taxa mínima atrativa (TMA) ao ano & $6,46 \%$ \\
\hline Tempo de vida útil & 25 anos \\
\hline Manutenção preventiva anual & $0,50 \%$ \\
\hline Uma troca dos inversores após o ano 15 & $\mathrm{R} \$ 1.092 .000,00$ \\
\hline
\end{tabular}

Na Tabela 8 está o resultado do cálculo da viabilidade econômica para investimento próprio.

Tabela 8: Resultados da viabilidade econômica com investimento próprio.

\begin{tabular}{ll} 
VPL & $\mathrm{R} \$ 7.812 .480,81$ \\
\hline TIR & $27,53 \%$
\end{tabular}


Para estimar os resultados das análises econômicas no segundo cenário, oriundos de empréstimos ao poder público, as taxas de juros podem variar de acordo com o programa de linha de crédito. Para o cálculo, foi verificada a linha de crédito divulgada para essa finalidade pelo Banco Nacional do Desenvolvimento BNDES, com uma simulação de crédito no próprio site, conforme Figura 7. O financiamento é de $90 \%$ do valor total do investimento, 10\% de contrapartida com recurso próprio, carência de 03 meses, prazo total de 120 meses ou 10 anos, taxa de juros de 10,44\% ao ano e amortização de R\$ 28.557,69 ao mês.

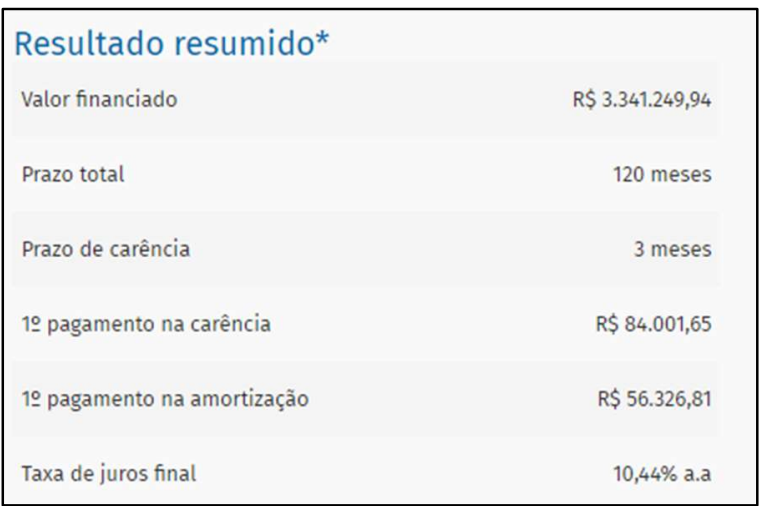

Figura 7: Simulação de linha de crédito do BNDES.

Na Tabela 9, está o resultado do cálculo da viabilidade econômica para investimento através de linha de crédito.

Tabela 9: Resultados da viabilidade econômica com financiamento.

\begin{tabular}{lc}
\hline VPL & $\mathrm{R} \$ 7.197 .160,31$ \\
\hline TIR & $49,64 \%$ \\
\hline Payback simples em anos & 2,26 \\
\hline Payback descontado em anos & 2,53 \\
\hline LCOE (final do período de 25 anos) & $\mathrm{R} \$ 0,20$ por kWh produzido \\
\hline
\end{tabular}

No terceiro cenário de modalidade por registro de preço, a Tabela 10 demonstra a viabilidade econômica de uma simulação de aquisição gradual, e por um período de 7 anos, que serão capazes de gerar $219 \mathrm{kWh} /$ ano a cada 30 kits instalados. Esse cenário será capaz de atender a demanda de consumo total a partir do 7음 ano.

Tabela 10: Viabilidade econômica em um cenário de aquisição de 30 kits anuais.

\begin{tabular}{lc} 
VPL & $\mathrm{R} \$ 6.175 .761,37$ \\
\hline TIR & $27,33 \%$ \\
\hline Payback simples em anos & 6,35 \\
\hline Payback descontado em anos & 6,74 \\
\hline LCOE (final do período de 25 anos) & $\mathrm{R} \$ 0,17$ por kWh produzido
\end{tabular}

A Figura 8 demonstra a evolução do VPL e da TIR pelo período de 25 anos nos três cenários: com investimento inicial próprio total, por financiamento e por investimento gradual de 30 kits anuais por 7 anos. 


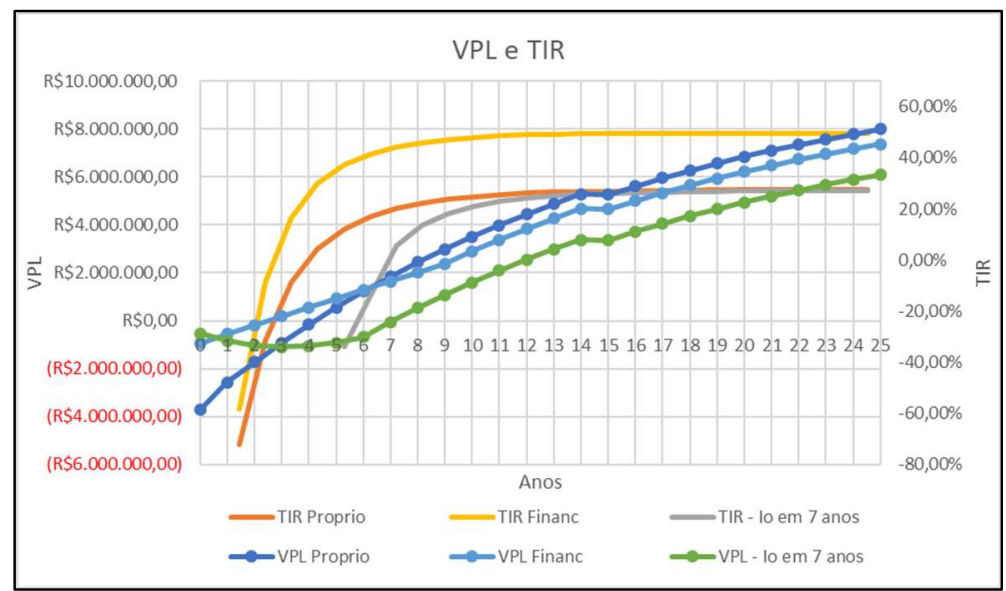

Figura 8: VPL e TIR com investimento próprio, financiamento e gradual por 7 anos.

A Figura 9 demonstra a evolução do LCOE e da tarifa da concessionária nos cenários com investimento próprio e por financiamento e também da geração energética anual pelo período de 25 anos. Nota-se que a evolução da produção energética é gradual para aquisição parcelada de 30 kits de sistemas fotovoltaicos ao ano.

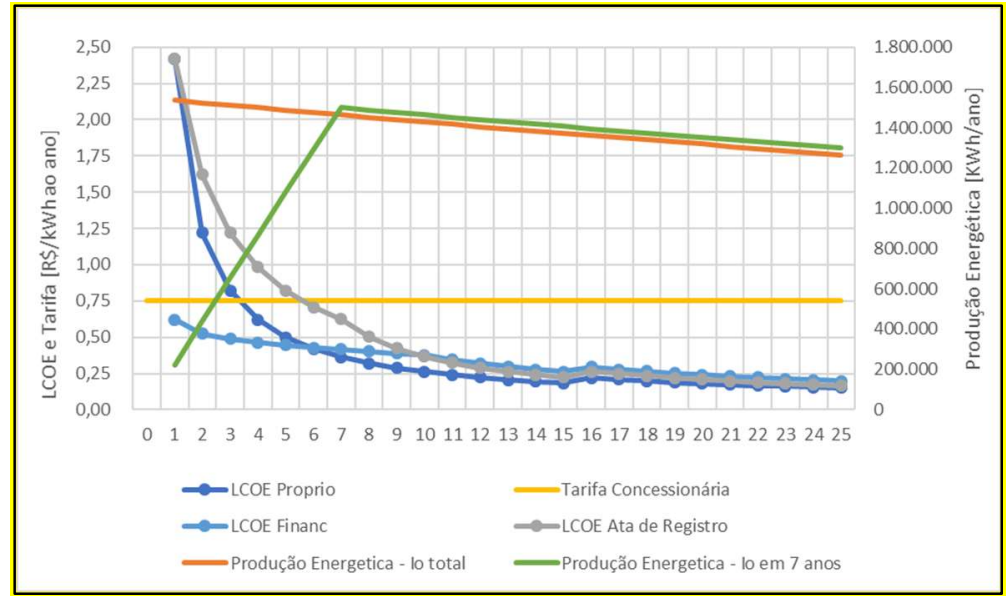

Figura 9: Comparativo do LCOE, da tarifa e da produção.

Ao incorporar os sistemas fotovoltaicos nos locais indicados, pretende-se reduzir a demanda de energia elétrica por parte do município, aliviando a demanda no sistema elétrico interligado à rede da concessionária. O potencial de geração energética dos sistemas fotovoltaicos instalados nos 55 prédios públicos iniciais é de 5,1 GWh ao ano, com ocupação dos telhados de 40\%. Isso representa uma geração de, aproximadamente, 3,7 milhões de reais ao ano considerando as tarifas atuais. Porém, para atender a demanda atual de consumo de toda a administração dos 189 edifícios de Itajubá - excluindo-se a sede administrativa que possui contrato sob demanda em alta tensão e da iluminação pública, a qual rege sob regulamentos específicos - é necessário gerar 1,5 GWh/ano para suprir o consumo atual, sendo necessária a implementação do sistema fotovoltaico nos 55 prédios com 210 kits contendo 01 inversor de 4 kW e 12 placas fotovoltaicas de $405 \mathrm{Wp}$ cada, ocupando uma área total de $4.726 \mathrm{~m}^{2}$, ou $11 \%$ da área total dos telhados.

A estimativa de mercado para aquisição e instalação do sistema fotovoltaico é de um total de 3,7 milhões de reais para geração de $1,05 \mathrm{MWp}$, ou quase $1,5 \mathrm{GWh} /$ ano gerados para atender o consumo atual 
de 189 unidades consumidoras. Com investimento próprio, a prefeitura terá seu valor investido de volta em 4,14 anos, se considerarmos as taxas de amortização. No período de 25 anos, o Valor Presente Líquido é positivo, com a Taxa Interna de Retorno de 27,53\% maior que a TMA e com LCOE inicial de $\mathrm{R} \$ 2,42$ por $\mathrm{kWh}$ gerado, que passa a ser menor que a tarifa da concessionária a partir do 4 o ano do investimento e com o valor de $\mathrm{R} \$$ 0,15 por kWh no final da vida útil do sistema.

O investimento inicial com recursos próprios para linha de crédito é de $10 \%$ de contrapartida, com 90\% financiados, e as parcelas do financiamento não ultrapassam a economia do retorno gerado pelo sistema. Ainda assim, os resultados da TIR verificam que a taxa ficou em 49,64\%, com payback de 2,53 anos. Sua atratividade foi inferior apenas no método LCOE, dentre os 3 cenários, que foi de $\mathrm{R} \$ \mathbf{0 , 2 0}$ por kWh gerado projetado para o final da vida útil de 25 anos do sistema. Porém, esse cenário teve o LCOE menor que a tarifa da concessionária desde o início do projeto.

Para o terceiro cenário proposto, adequado para aquisição pública através de ata de registro de preço com aquisição de 30 kits do sistema fotovoltaico ao ano, o VPL e a TIR são os menores dentre os cenários e com 6,74 anos para o retorno do investimento inicial. Contudo, é um investimento atrativo, com TIR de 28,74\% e LCOE inicial de R\$ 2,42 por kWh gerado, tornando-se menor que a tarifa da concessionária a partir do 6 o ano e de $\mathrm{R} \$$ 0,17 por kWh gerado no final da vida útil do sistema.

\section{CONCLUSÕES}

Um grande potencial de geração foi notado no setor de geração fotovoltaico, de modo que a prefeitura de Itajubá poderá obter sua autossuficiência e, desta forma, também participará da mitigação dos impactos sociais e ambientais da geração de energia. Em qualquer um dos cenários de investimento apresentados, mesmo com endividamento inicial considerável do município, o montante que não seria mais gasto com contas de energia elétrica poderá ser investido em programas de melhoria energética, equipamentos mais eficientes e outros projetos, em um período curto após implantação: a partir do 4o ano com recursos próprios, do 2으 ano e meio através de linha de crédito ou a partir do 7으 ano, se forem realizadas aquisições modulares para a implantação do sistema. Torna-se mais atrativo ao longo da vida útil do sistema se o valor gasto com a implantação dessa tecnologia for oriundo de recursos financiados através de linha de crédito do BNDES, pois todos os indicadores econômicos são melhores nesse cenário, em comparação aos demais desde o início da implantação do sistema, mesmo havendo taxa de juros de 10,44\% ao ano, com exceção do LCOE, no final dos 25 anos, que ficou desfavorável nesse cenário.

Porém, segundo a Prefeitura Municipal de Itajubá, o montante de investimento próprio para a implantação do sistema fotovoltaico é cerca de 1,5\% da previsão orçamentária anual total do município e deve estar previsto na Lei orçamentária anual do município do ano anterior à aquisição. Além disso, para abertura de linha de crédito para financiamento, é necessário que o município tenha a aprovação da Câmara Municipal, sob estudo da saúde financeira e do poder de endividamento do município. A aquisição própria sob a contratação de registro de preço torna-se atraente, pois não há a necessidade de dotação orçamentária prévia para licitação, apenas na aquisição do sistema, e o endividamento inicial nesta modalidade pode ser 
diluído, já que o sistema poderá ser adquirido de forma modular e gradativo por um período de 1 ano ou ser novamente licitado após passado o período de validade da ata de registro de preço. Nesta modalidade, podese também incorporar a solicitação de aquisição no orçamento de outras secretarias do próprio município. Outros órgãos públicos, incluindo municípios, poderão aderir à ata de registro de preço para aquisição dos kits com um valor ainda mais atraente, devido ao volume maior de equipamento a ser licitado pela Prefeitura de Itajubá, se comparado com estes municípios, ao realizarem sua própria aquisição ou licitação.

Em se tratando de um órgão público, que é administrado sob leis e normas rígidas para tomadas de decisões, sugere-se antecipadamente a implantação de lei elaborada e aprovada pelo legislativo que regularize e torne obrigatório que a administração municipal implemente o sistema fotovoltaico em suas edificações públicas em um prazo determinado e que a economia gerada possa ser investida em outros segmentos, independentemente do governante do executivo eleito. Essa forma de obrigatoriedade prevista em lei já vem ocorrendo em alguns municípios, tal como em Ilhabela, no estado de São Paulo, onde o projeto de lei 101/2019 foi aprovado recentemente pela câmara municipal. De acordo com o texto do projeto da Câmara Municipal de Ilhabela (2020), os prédios públicos de propriedade do município devem ser equipados com painéis solares, no prazo máximo de cinco anos após a aprovação da lei, sendo 50\% em dois anos, 70\% em três anos e 100\% ao final do prazo e com emenda impositiva à Lei Orçamentária Anual para 2020 (LOA), destinando valor de até $\mathrm{R} \$ 2.450 .660,00$ para realização de projeto de instalação de placa fotovoltaica para energia solar nos prédios públicos de Ilhabela.

\section{REFERÊNCIAS}

ANEEL. Agência Nacional de Energia Elétrica. Banco de informações de geração: fontes de energia exploradas no Brasil. ANEEL, 2020.

ANEEL. Agência Nacional de Energia Elétrica. Evolução das tarifas. ANEEL, 2020.

ANEEL. Agência Nacional de Energia Elétrica. Informações técnicas capacidade instalada micro e minigeração distribuída. ANEEL, 2020.

BHANDARI, K. P.; COLLIER, J. M.; ELLINGSON, R. J.; APUL, D. S.. Energy payback time (EPBT) and energy return on energy invested (EROI) of solar photovoltaic systems: A systematic review and meta-analysis. Renewable and Sustainable Energy Reviews, v.47, p.133-141, 2015. DOI: http://doi.org/10.1016/i.rser.2015.02.057

ILHABELA. Câmara Municipal de Ilhabela-SP. Projeto de Lei n. 101/2019. Dispõe sobre a utilização de energia fotovoltaica em todos os prédios públicos do município de Ilhabela e dá outras providências. Ilhabela, 2020.

CARVALHO, F. S.; LAGE, E. G. S.. Analysis and dimensioning method of the ongrid photovoltaic system. Technology Science, v.1, p.24-36, 2019. DOI http://doi.org/10.6008/CBPC2674-6425.2019.002.0004

EPE. Empresa de Pesquisa Energética. Nota Técnica DEA
13/14: Demanda de Energia 2050. Brasília: EPE, 2014.

EPE. Empresa de Pesquisa Energética. Nota Técnica EPE: Análise da Inserção da Geração Solar na Matriz Elétrica Brasileira. Brasília: EPE, 2012.

HOLDERMANN, C.; KISSEL, J.; BEIGEL, J.. Distributed photovoltaic generation in Brazil: An economic viability analysis of small-scale photovoltaic systems in the residential and commercial sectors. Energy Policy, v.67, p.612-617, 2014. DOI:

http://doi.org/10.1016/i.enpol.2013.11.064

ONDRACZEK, J.; KOMENDANTOVA, N.; PATT, A.. WACC the dog: The effect of financing costs on the levelized cost of solar PV power. Renewable Energy, v.75, p.888-898, 2015.

RÜTHER, R.; ZILLES, R.. Making the case for grid-connected photovoltaics in Brazil. Energy Policy, v.39, p.1027-1030, 2011.

TALAVERA, D. L.; NOFUENTES, G.; AGUILERA, J.. The internal rate of return of photovoltaic grid-connected systems: $A$ comprehensive sensitivity analysis. Renewable Energy, v.35, n.1, p.101-111, 2010. DOI: http://doi.org/10.1016/j.renene.2009.07.006

TOLMASQUIM, T. T.. Energia Renovável: Hidráulica, Biomassa, Eólica, Solar, Oceânica. Rio de Janeiro: EPE, 2016.

A CBPC - Companhia Brasileira de Produção Científica (CNPJ: 11.221.422/0001-03) detém os direitos materiais desta publicação. Os direitos referem-se à publicação do trabalho em qualquer parte do mundo, incluindo os direitos às renovações, expansões e disseminações da contribuição, bem como outros direitos subsidiários. Todos os trabalhos publicados eletronicamente poderão posteriormente ser publicados em coletâneas impressas sob coordenação da Sustenere Publishing, da Companhia Brasileira de Produção Científica e seus parceiros autorizados. Os (as) autores (as) preservam os direitos autorais, mas não têm permissão para a publicação da contribuição em outro meio, impresso ou digital, em português ou em tradução. 